\title{
Ultrastructural differentiation of the genogroups in the genus Ehrlichia
}

\author{
V. L. POPOV, VIOLET C. HAN, S.-M. CHEN, J. S. DUMLER*, H.-M. FENG, T. G. ANDREADIS†, \\ R. B. TESH and D. H. WALKER
}

WHO Collaborating Center for Tropical Diseases and Department of Pathology, University of Texas Medical Branch, Galveston, TX 77555 - 0609, *Division of Medical Microbiology, Department of Pathology, Johns Hopkins Medical Institutions, Baltimore, MD 21287 and + Department of Soil and Water, Connecticut Agricultural Experiment Station, New Haven, CT 06504, USA

\begin{abstract}
Ultrastructural characteristics of 15 strains and isolates of ehrlichiae belonging to three genogroups, or clades of genetically related organisms united in the genera Ehrlichia, Cowdria, Anaplasma, Neorickettsia and a strain of Wolbachia pipientis which represents a fourth genogroup in this cluster of species, were studied in continuous cell culture or in vivo: $E$. canis (Oklahoma strain and VHE isolate), E. muris (AS 145), E. chaffeensis (Arkansas, 91HE17 and Sapulpa), human granulocytic ehrlichiae (HGE)(BDS, 96HE27, 96HE37, \#54, \#55 and \#72), E. equi (MRK), E. sennetsu (Miyayama), E. risticii (HRCIL). Wolbachia pipientis was studied in the naturally infected Aedes albopictus mosquito cell line Aa23. All organisms were similar in the normal ultrastructure of individual cells and in the ability to form abnormal, pathological ehrlichial cells of the same type irrespective of the species. Normally all ehrlichiae studied in cell culture existed in two morphological forms - reticulate and dense-cored cells, both of which could divide by binary fission. Most alterations were related to their membranes, especially the cell wall. Differences in the structure of intravacuolar microcolonies (morulae) of ehrlichiae and their inter-relations with the host cells allowed differentiation of the genogroups: the $E$. canis-E. chaffeensis- $E$. muris genogroup formed large morulae, with many ehrlichiae, often suspended in a fibrillar matrix, and the host cell mitochondria and endoplasmic reticulum usually aggregated near the morulae and were in contact with the morula membrane; the $E$. phagocytophila-E. equi-HGE group morulae had no fibrillar matrix, no contacts with host cell mitochodria, and they did not aggregate around the morulae; E. sennetsu-E. risticii group usually developed in small individual vacuoles that did not fuse with each other and divided along with the ehrlichiae.
\end{abstract}

\section{Introduction}

Micro-organisms classified in the genus Ehrlichia of the family Rickettsiaceae are small gram-negative obligately intracellular bacteria parasitising either peripheral blood monocytes or granulocytes of animals and man where they multiply inside a modified parasitophorous endosome. They are transmitted to their hosts by ticks [ $1-4]$ in which they spend a poorly described part of their life-cycle.

Until the last decade ehrlichiae were recognised mostly as agents of veterinary importance except $E$.

Received 27 June 1997; accepted 15 July 1997. Corresponding author: Professor D. Walker. sennetsu, the agent of Sennetsu fever, which has limited recognised prevalence in Japan and Malaysia [5]. The first human case of monocytic ehrlichiosis was identified in the USA in 1986 [6], in 1991 isolation of the aetiological agent of the disease, $E$. chaffeensis, was first reported [7], and the agent of human granulocytic ehrlichiosis was identified in 1994 [8].

According to the relatedness of the $16 \mathrm{~S}$ rRNA gene sequences, the species currently united in the genus Ehrlichia are separated into three genogroups [7, 9]. Three other genera of rickettsiae formerly classified in different tribes and families, Cowdria, Anaplasma and Neorickettsia appear to be closely related to ehrlichiae in these genogroups. The E. canis genogroup also contains the human pathogen, $E$. chaffeensis, a canine 
granulocytic ehrlichia, E. ewingii, a recently described murine pathogen, E. muris $[10,11]$, and the agent of heartwater disease, $C$. ruminantium $[12-16]$. The second genogroup consists of a closely related cluster:

$E$. equi, E. phagocytophila, the agent of tick-borne fever in goat and sheep, and the human granulocytic ehrlichia (HGE), that might comprise one species [17]; E. platys infecting platelets of dogs [18]; and the Anaplasma species, $A$. marginale and $A$. ovis [19-21]. The third genogroup is represented by $E$. sennetsu, E. risticii, the agent of Potomac horse fever, or equine monocytic ehrlichiarosis, another equine pathogen that might be classified as a separate species, Ohio 081 isolate [22], and two Neorickettsia species, that parasitise flukes, by which dogs that consume fluke-infested fish are infected [23, 24]. A similar ehrlichia, the SF-agent, was isolated from a fluke, Stellantchamus falcatus, with no known associated disease [25].

Only recently have most of the ehrlichiae been propagated in cell culture systems [24-29], which has permitted more detailed studies of their biology and ultrastructure $[5,11,22-39]$. Nevertheless, knowledge about the fine structural morphology of the ehrlichiae belonging to the three genogroups remains fragmentary, and no comparison between them has been published.

The aims of this report are: to describe the ultrastructure of the newly isolated ehrlichiae; to compare the anatomy of different isolates (strains) within one species; and to compare the fine structure of ehrlichiae belonging to different species and different genogroups.

\section{Materials and methods}

\section{Ehrlichiae}

E. canis (Oklahoma strain) was obtained from Jacqueline Dawson (Viral and Rickettsial Zoonoses Branch, CDC, Atlanta, GA, USA). E. canis (Venezuelan isolate) and E. muris (AS145 strain) were kindly provided by Yasuko Rikihisa (Ohio State University, Columbus, $\mathrm{OH}, \mathrm{USA}$ ). E. chaffeensis (Arkansas strain) was provided by Jacqueline Dawson. E. chaffeensis $91 \mathrm{HE} 17$ and Sapulpa strains were isolated in the laboratory at the University of Texas Medical Branch $[38,40]$. Human granulocytic ehrlichiae (HGE) strains BDS, 96HE27, 96HE37, \#54, 55 and 72 were isolated in the laboratory at the Johns Hopkins Medical Institutions. E. equi (MRK strain) was obtained from J.E. Madigan (University of California, Davis, CA, USA). E. sennetsu (Miyayama strain) was kindly provided by C. Pretzman (Ohio State University, Columbus, OH, USA). E. risticii (HRC-IL strain) was obtained from the American Type Culture Collection. Wolbachia pipientis was studied in the mosquito Aedes albopictus cell line Aa23, established at the Yale
University School of Medicine (New Haven, CT, USA) [41].

\section{Propagation of ehrlichiae}

Cell cultures. Most of the ehrlichiae were cultivated in DH82 cells, a canine macrophage cell line, in Eagle's minimum essential medium (EMEM) containing fetal bovine serum $10 \%, 26 \mathrm{mM}$ sodium bicarbonate and $2 \mathrm{mM}$ glutamine at $34^{\circ} \mathrm{C}$. E. muris was propagated in the $\mathrm{P}_{338 \mathrm{D}_{1}}$ macrophage cell line in Dulbecco's modified Eagle's medium (DMEM) with fetal bovine serum $10 \%$. HGE were isolated in HL60 human myeloid leukaemic cell line (ATCC CCL240) cultivated in RPMI 1640 medium supplemented with heatinactivated fetal calf serum $10 \%$ and $2 \mathrm{mM}$ glutamine at $37^{\circ} \mathrm{C}$ in an atmosphere of $\mathrm{CO}_{2} 5 \%$ in air [28] by continuous passages for 1-2.5 months. A continuous cell line Aa23 was established from the eggs of a Houston strain of the Asian tiger mosquito, Aedes albopictus (kept at Yale University), naturally infected with the intracellular symbiont $W$. pipientis. The growth medium consisted of equal volumes of MitsuhashiMaramorosh and $\mathrm{VP}_{12}$ media supplemented with heatinactivated fetal bovine serum $15 \%$. Once established, cells were grown in $2.5-\mathrm{ml}$ flasks at $26^{\circ} \mathrm{C}$. Cells were passaged every 4-5 days by vigorous shaking followed by low speed centrifugation, replacement of spent medium and seeding new flasks with $20 \%$ of the resuspended cells [41].

Inoculation of mice. $\mathrm{BALB} / \mathrm{c}$ mice were inoculated intraperitoneally with $E$. muris-infected DH82 cell suspension (originally from Yasuko Rikihisa) or $10 \%$ splenocyte suspension from a day 10-infected mouse.

Inoculation of horses. E. equi and BDS strain of HGE were studied in neutrophils purified from the buffy coat of intravenously inoculated horses after they developed clinical signs of an ehrlichial infection (usually between days 5 and 10 after inoculation) [42]. For HGE, a sample of fresh, acute stage whole blood from a patient with clinical symptoms of HGE, containing Ehrlichia morulae in $15 \%$ of the neutrophils, was inoculated intravenously into a healthy 2-year-old thoroughbred stallion. The horse was housed in a vector-proof facility and was $E$. equi-seronegative at the start of the experiment.

\section{Electron microscopy}

Cell cultures, pellets of neutrophils and small pieces of tissues were fixed in a mixture of formaldehyde $1.25 \%$, glutaraldehyde $2.5 \%$ and trinitrophenol $0.03 \%$ in $0.05 \mathrm{M}$ cacodylate buffer, $\mathrm{pH} 7.3$ [43], processed further as described earlier [37] until embedding in Poly/Bed 812 (Polysciences Inc., Warrington, PA, USA). Some Wolbachia-infected cultures were also fixed at $4{ }^{\circ} \mathrm{C}$ in glutaraldehyde $2.5 \% \mathrm{v} / \mathrm{v}$ containing $\mathrm{CaCl}_{2} 0.1 \% \mathrm{w} / \mathrm{v}$ and sucrose $1 \% \mathrm{w} / \mathrm{v}$ in $100 \mathrm{mM}$ 
sodium cacodylate buffer ( $\mathrm{pH}$ 7.3) and post-fixed in $\mathrm{OsO}_{4} 1 \% \mathrm{w} / \mathrm{v}$, stained en bloc with uranyl acetate $2.0 \% \mathrm{w} / \mathrm{v}$, dehydrated through an ethanol and acetone series, and embedded in an LX-112/Araldite (Ladd Research Industries, Burlington, VT, USA) mixture. Ultra-thin sections were cut with a Sorvall MT-6000 ultramicrotome (Sorvall Instruments, Tucson, AZ, USA), stained with aqueous uranyl acetate $2 \%$ and lead citrate $0.4 \%$ and examined in a Philips 201 electron microscope (Philips Electron Optics, Eindhoven, The Netherlands) at $60 \mathrm{kV}$.

\section{Results}

\section{E. canis}

E. canis developed in the cytoplasm of the host macrophages (DH82 cells) in multiple parasitophorous vacuoles (morulae). Each of them usually contained a homogeneous population of either of two morphological forms of ehrlichiae: reticulate cells or dense-cored cells (Fig. 1A). Morulae were of different sizes, those filled with large quantities of bacteria (30-60 profiles in ultra-thin section) measured $2-4 \mu \mathrm{m}$ in diameter. Usually, reticulate cells were more densely packed in the morula than dense-cored ehrlichiae. Both kinds of vacuoles - those containing only reticulate cells, and those with dense-cored ehrlichiae - were filled with fibrillar matrix between the ehrlichial cells (Figs. 1A, 2A).

Reticulate cells were small, oval bacteria, with average minimal and maximal diameters of 0.3 and $0.6 \mu \mathrm{m}$, respectively, surrounded by two limiting membranes: an outer cell-wall membrane and inner cytoplasmic membrane. The cell-wall membrane often had a wavy appearance and was separated from the cytoplasmic membrane by a narrow periplasmic space. The protoplast of reticulate cells was filled with ribosomes and a meshwork of DNA fibrils, forming a reticulate nucleoid. Reticulate cells were observed in the process of division by binary fission.

Dense-cored cells were round with a diameter of $0.3-$ $0.4 \mu \mathrm{m}$. Some of them were of irregular, pleomorphic shape. Usually, ehrlichiae of the latter type were more loosely packed in the morula. Dense-cored cells also had a cell-wall membrane and a cytoplasmic membrane.

The ehrlichial morphology described above is characteristic and thus can be considered as the normal structure. In some infected cells, other structures were found. Those appeared to be reticulate cells with large expansions of the periplasmic space, vesicles or long tubules, or both, originating from the cell-wall membrane (Fig. 1B), and long projections of the whole ehrlichial envelope including both limiting membranes, cytoplasmic and cell wall, all of which were observed inside morulae between the ehrlichiae
(Fig. 1C). Vesicles of different diameters, but usually about $150 \mathrm{~nm}$, were observed frequently in the morula cavities. They were seen pinching off the cell-wall membrane (Fig. 1B). Tubules of a constant diameter (25 $\mathrm{nm}$ in cross-section) had variable lengths, sometimes almost the whole length of the parental reticulate cell (Fig. 1B). Envelope projections in some instances surrounded the whole parental reticulate cell or the neighbouring ehrlichia, thus creating a complex multimembranous structure (Fig. 1C). The abnormality most commonly seen in dense-cored cells was invagination of the cell-wall membrane into the protoplast (Fig. 2A), thus separating a portion of it.

The host cell cytoplasm did not seem to be altered morphologically by the development of the ehrlichiae. Unlike what was previously described for $E$. chaffeensis Arkansas strain [37], mitochondria were not observed adjacent to the morulae. Cisterns of granular endoplasmic reticulum were frequently tightly apposed to the morula membrane along with some cytosolic vesicles (Fig. 1A).

Morulae containing irregularly shaped dense-cored cells were observed close to the plasmalemma of the host cell. In some of them rupture of the morular limiting membrane and plasmalemma occurred, thus releasing ehrlichial progeny out of the host cell. The adjacent portions of the host cell cytoplasm seemed not to have been damaged (Fig. 2A).

\section{Human isolate of $E$. canis}

The Venezuelan human isolate of $E$. canis [44] in DH82 cells formed smaller morulae containing ehrlichial reticulate cells and larger vacuoles with dense-cored cells. Small morulae contained from one to several densely packed reticulate cells. Some of them were observed in the process of dividing into unequal halves. Some reticulate cells had intraprotoplast invaginations of the cytoplasmic membrane (Fig. 2B).

Morulae with dense-cored cells were loosely packed, and their cavity was filled with tiny fibrils (Fig. 2C). Some dense-cored cells had intraprotoplastic invaginations of their cytoplasmic membrane.

\section{E. muris}

We were not able to propagate E. muris in DH82 cells; therefore, its ultrastructure was studied in the lungs, spleen, liver and kidney of intraperitoneally infected mice and in the $\mathrm{P}_{338 \mathrm{D}_{1}}$ murine macrophage cell line. Ehrlichiae were found in monocytes-macrophages of the lung, spleen and kidney, in neutrophils in liver and spleen, and in eosinophils in lung. They formed morulae, not exceeding $3 \mu \mathrm{m}$ in diameter, filled only with typical reticulate cells (Fig. 2D). Morulae containing dense-cored cells were not found in mice. 

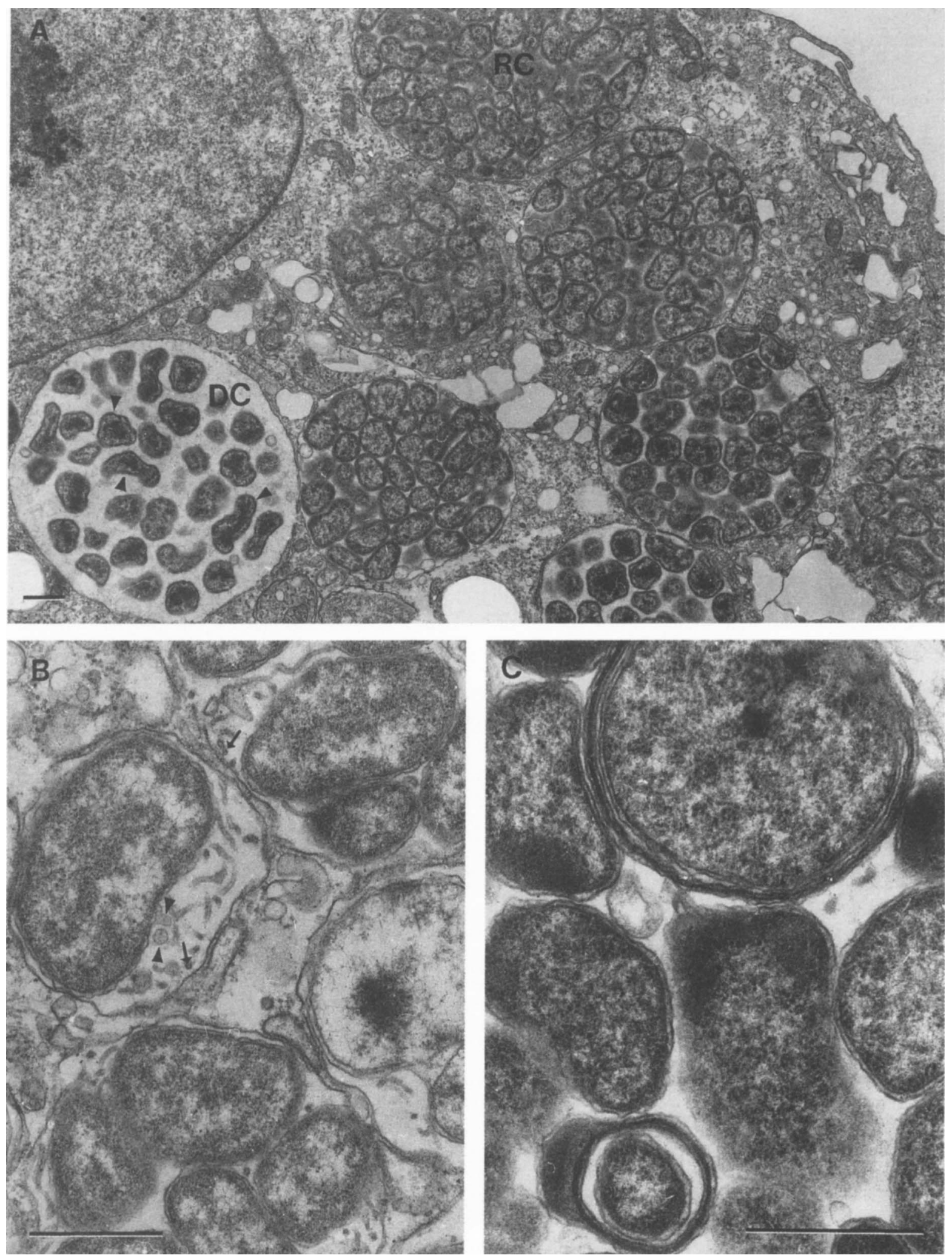

Fig. 1. Ultrastructure of $E$. canis (Oklahoma strain) in canine histiocytoma cell line DH82. Bar $=0.5 \mu \mathrm{m}$. A, The cytoplasm contains eight ehrlichial morulae harbouring either reticulate cells (RC) or dense-cored cells (DC). In one morula DC have irregular shape (arrowheads). B, Morulae contain RC from which cell-wall membranes have pinched off vesicles (arrowheads), or form long tubules of uniform diameter $25 \mathrm{~nm}$ (arrows show their cross-sections). C, Two RC develop protrusions of limiting membranes with a thin rim of cytoplasm between them that envelope whole ehrlichiae.

Reticulate cells had a typical wavy cell-wall membrane loosely adjacent to the cytoplasmic membrane thus forming a clearly visible periplasmic space of variable width. Some reticulate cells were in the process of equal binary fission. The morula cavity was filled with small vesicles and a varying quantity of fibrils. Only a few host cell mitochondria were observed in close contact with the morula membrane. 

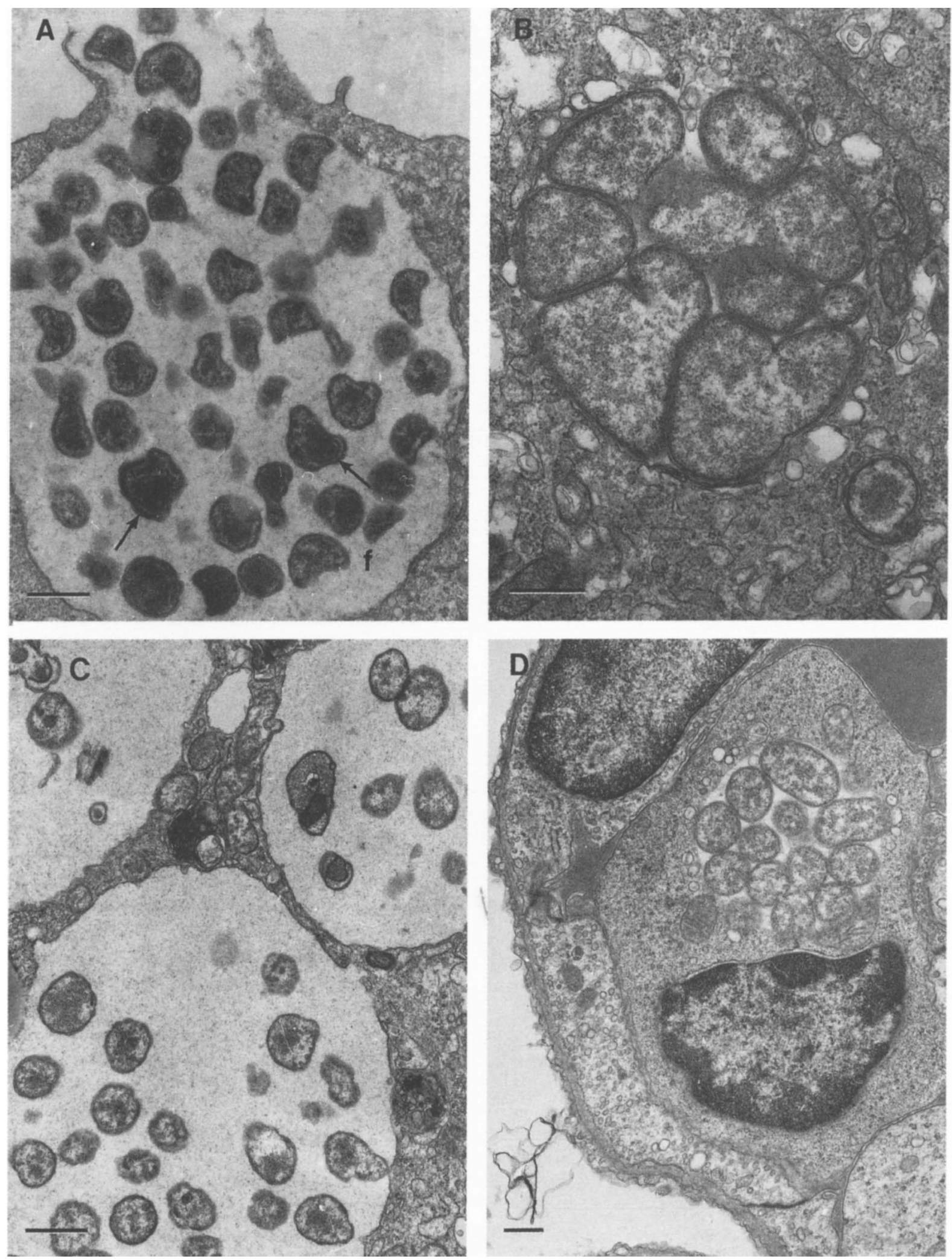

Fig. 2. E. canis and E. muris in host cells. Bar $=1 \mu \mathrm{m}$. A, Exit of E. canis DC from a morula through the rupture of the morula membrane, host cell cytoplasmic rim and plasmalemma of a DH82 cell. Most DC in the morula have an irregular shape. Some DC show intraprotoplast invaginations of their cytoplasmic membrane, sequestrating portions of their protoplast (arrows). DC in the morula are embedded in fibrillar matrix (f). B, Venezuelan human isolate (VHE) of $E$. canis in DH82 cells. Large morula contains RC, densely packed and dividing by unequal fission; a small morula has one DC-like cell. C, VHE in Vero cell are present in large morulae with loosely distrubuted DC, in a fibrillar matrix. D, E. muris (AS145 strain) in a pulmonary macrophage of a BALB/c mouse (10 days after infection) is observed in a morula containing only RC. 
In $\mathrm{P}_{338 \mathrm{D}_{1}}$ cells, E. muris formed morulae containing reticulate cells or dense-cored cells, or both, and both forms were found dividing. The morula cavities contained fibrillar matrix, including long, parallel arrays of fibrils. Larger reticulate cells had long tubules originating as projections of the cell-wall membrane or the whole envelope, or both. Vesicles of different sizes were also encountered inside the vacuoles (Fig. 3A). Host cell mitochondria were concentrated near the morulae.

\section{Human monocytic ehrlichia - E. chaffeensis}

The ultrastructure of all three reported human isolates has been described previously [37, 38, 40], but until now they have not been compared. All three strains developed both normal and altered reticulate and dense-cored cells in morulae in DH82 cells, as has been described in most detail for Arkansas strain [37]. The cell-wall membrane of reticulate cells of all three strains pinched off vesicles into the morula cavity and grew out tubules of uniform diameter $(25 \mathrm{~nm})$. Morula cavities were also filled with fibrillar matrix of different densities, less abundant in strain 91HE17. Most morulae contained a uniform population of either reticulate or dense-cored cells, although in Arkansas strain morulae the presence of both forms in the same morula was not rare. As in other Ehrlichia species studied, all these appearances of morulae were detected in the cytoplasm of the same host cell. Mitochondria and cisterns of granular endoplasmic reticulum had a tendency to concentrate around morulae and to form contacts with the morula membrane.

\section{Human granulocytic ehrlichiae}

Five patient isolates in HL60 cells (human myeloid precursor cell line) and one isolate in horse neutrophils after infection of a healthy horse with human patient blood [42] were examined. Isolate 96HE27 was examined after cultivation in HL60 cells for 2.5 months; isolate 96HE37, after 1.5 and 2 months; isolates nos. 54 and 55, after 3 weeks; and isolate no. 72 after 2 weeks.

All isolates of HGE formed predominantly small (1.5-2.5 $\mu \mathrm{m}$ in diameter) morulae in both HL60 cells and horse neutrophils, but some morulae reached $6 \mu \mathrm{m}$ in diameter. Most morulae contained either only reticulate cells or only dense-cored cells (Figs. 3B, 4A). Only in isolate no. 54 did some large morulae harbour both cell types (Fig. 4B). Both ehrlichial cell types were observed in the process of binary fission (Figs. 3B, 4A), and many ehrlichiae of both cell types had a very wavy and loose cell wall, so that their periplasmic space was expanded. Many reticulate cells of all five isolates, either occupying the morula individually or with several reticulate cells in one morula, had a large size, up to $2 \mu \mathrm{m}$ in diameter.
These large cells were found dividing both equally and unequally (Fig. 4A, B).

Some morulae contained empty vesicles of different sizes, some of which were seen pinching off the cellwall membrane, but accumulation of fibrillar matrix was not detected in any of the isolates.

Both reticulate and dense-cored cells of all the isolates examined developed abnormal altered forms. Reticulate cells formed protrusions of the cytoplasmic membrane into the periplasmic space or invaginations into the protoplast (Figs. 3B, 4A). Invaginations of this kind in dense-cored cells led to fragmentation of the protoplast. Cell-wall membrane of some reticulate cells developed long projections, sometimes enveloping the whole ehrlichial cell, but these projections did not have a constant diameter, characteristic of the intramorular tubules in E. canis, E. muris and $E$. chaffeensis. In equine neutrophils, HGE reticulate cells were also observed forming protoplast buds into the periplasmic space [9].

There was no particular concentration of mitochondria or cisterns of granular endoplasmic reticulum observed around the morulae of HGE, although many cytoplasmic vesicles were in direct contact with the morula membranes. In fact, the HL60 cells were not rich in mitochondria.

\section{E. equi}

In equine peripheral blood neutrophils, small morulae that contained only a few reticulate cells were observed. Their cell walls were wavy and loose. The morula cavity frequently contained vesicles of different sizes, but was devoid of any matrix material (Fig. 5A).

Some reticulate cells formed protoplast buds or projections into the periplasmic space (Fig. 5A). In other cells, the cytoplasmic membrane invaginated into the protoplast, and in cross-sections these invaginations had a ring-like appearance. Very few morulae contained a single dense-cored ehrlichia.

In some instances the morula membrane was surrounded by perpendicularly arranged cytoplasmic microfilaments of 5-6 nm diameter (Fig. 5A).

\section{E. sennetsu}

The first stages of the interaction of this ehrlichia with the host cell were observed as small reticulate cells $(c$. $0.4 \mu \mathrm{m}$ in diameter), adherent to the surface of the plasmalemma or to the microvilli, but without the formation of tight contacts with them (Fig. 5B). The surface of some adherent ehrlichiae was covered with a fuzzy coat resembling the microcapsule of other bacteria (Fig. 5B, C). Reticulate cells were seen partially engulfed by the host cell microvilli or ruffles 

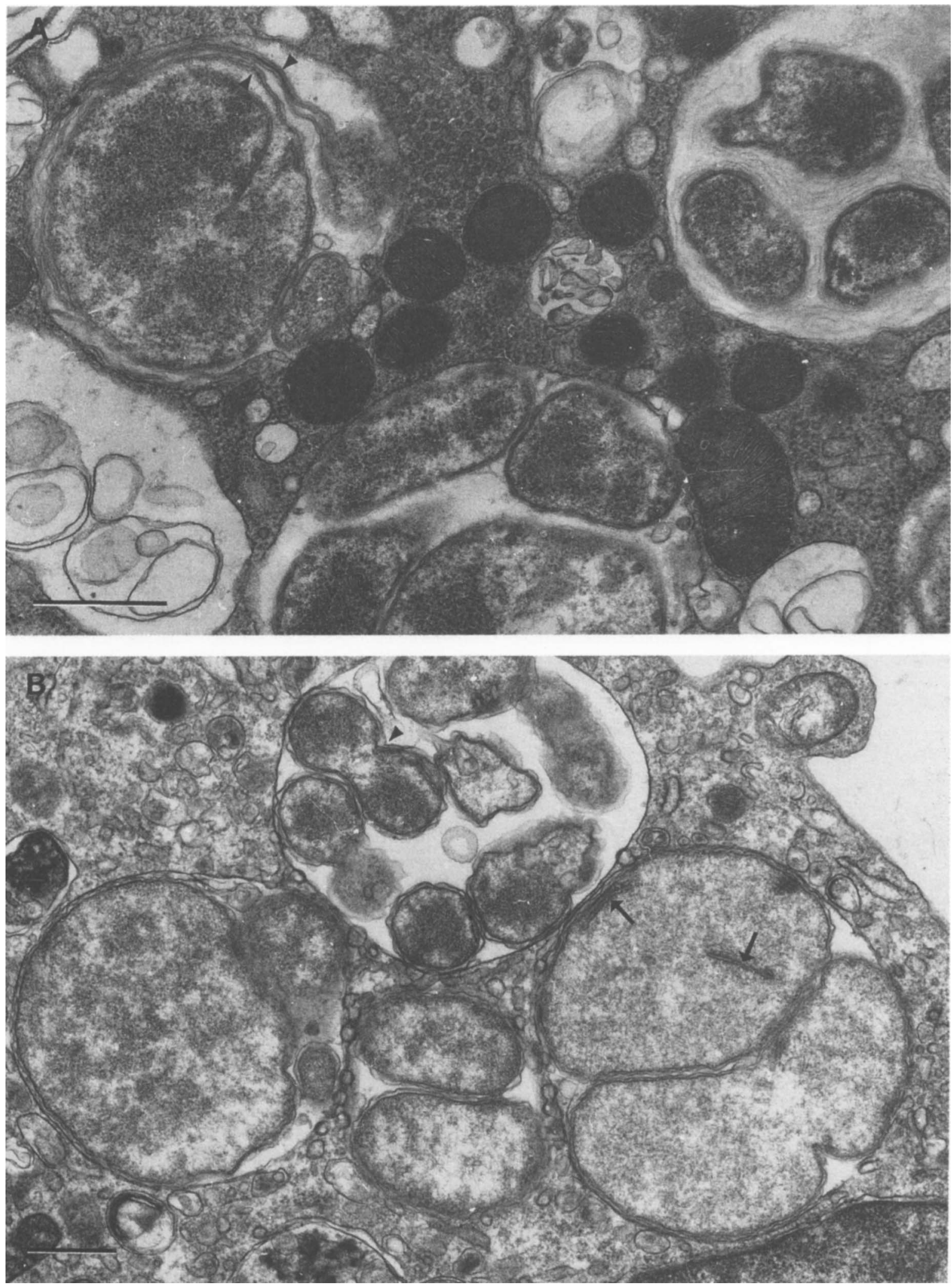

Fig. 3. E. muris and human granulocytic ehrlichiae (HGE) in cultured cells. Bar $=0.5 \mu \mathrm{m}$. A, E. muris (AS145 strain)

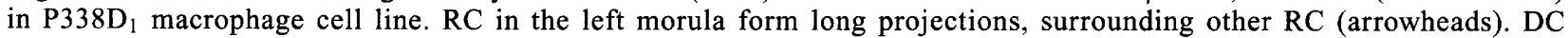
in the right morula are suspended in a fibrillar matrix. B, HGE (96HE27 strain) in promyelocyte HL60 cell line. Upper morula contains DC with wavy cell-wall membrane, one of which is dividing (arrowhead). Morula does not contain any matrix fibrils. Lower morulae harbour RC, one of which (the right one) is dividing, and the other has intracytoplasmic membrane invaginations (arrows). 

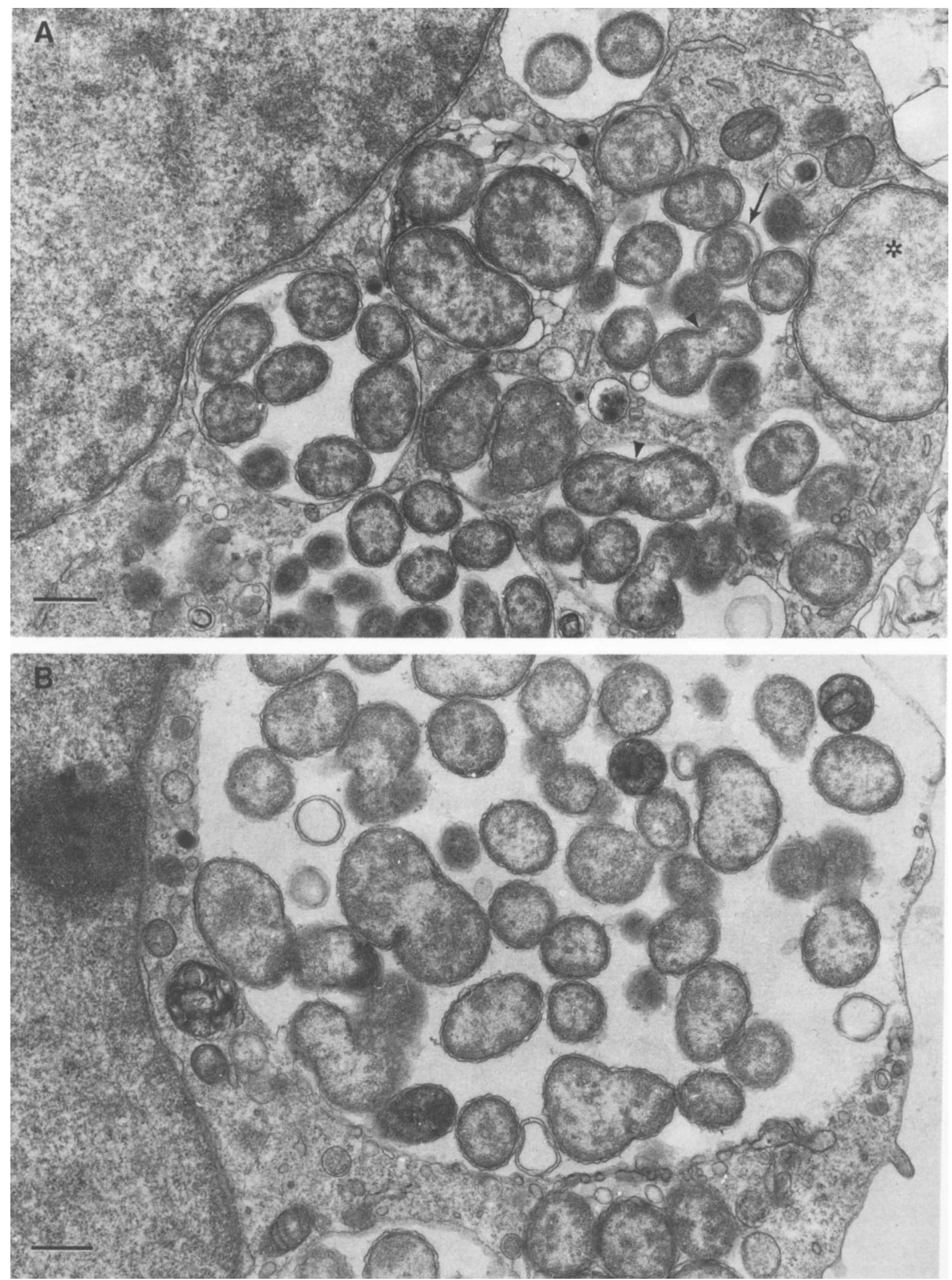

Fig. 4. Ultrastructure of HGE (strain \#54) in HL60 cells. Bar $=1 \mu \mathrm{m}$. A, Eleven morulae are seen in this section, all of them containing RC but having different sizes: from a giant (asterisk) to small ones. Some of them are dividing (arrowheads). One RC is surrounded by a membranous projection (arrow). B, Portion of a large morula and two smaller ones. Morula membrane and host cell cytoplasm are disrupted (in the upper right part), so only plasmalemma prevents ehrlichiae from exiting host cell. Neither of the morulae in either A or B has any matrix. 

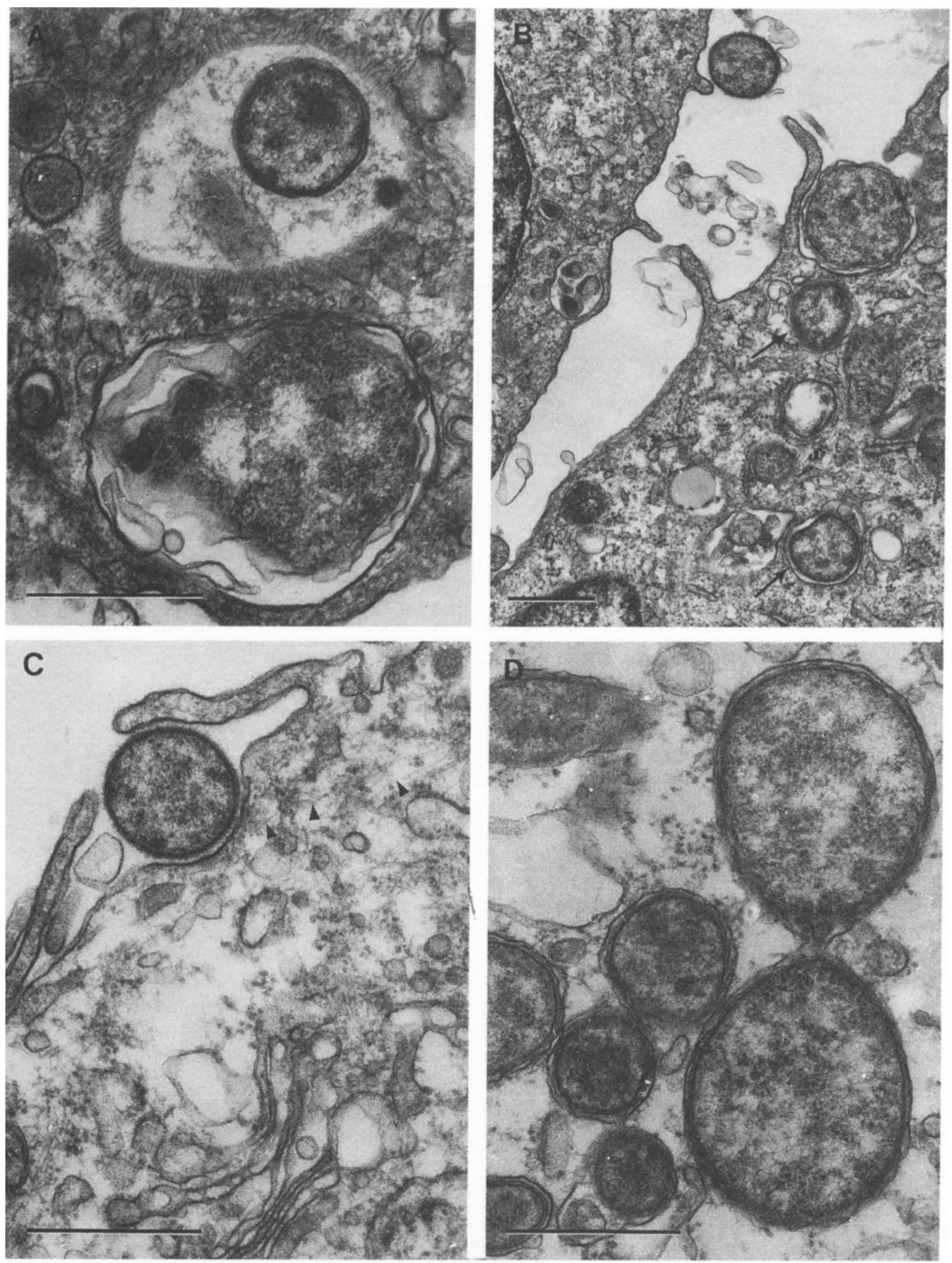

Fig. 5. E. equi (MRC strain) and E. sennetsu (Miyayama strain) in their host cells. Bars $=0.5 \mu \mathrm{m} . \mathbf{A}, E$. equi in a horse peripheral blood neutrophil. Upper morula contains a DC ehrlichia. The cytosol adjacent to the morula limiting membrane contains numerous perpendicularly oriented thin fibrils. $\mathrm{RC}$ in the lower morula has a very wavy cell-wall membrane and two protoplast buds protruding into its periplasmic space. B, E. sennetsu RC adhere to the cell surface (upper cell) and is being phagocytosed (lower cell) by a cell ruffle. Two other ehrlichiae are already inside phagosomes (arrows). C, E. sennetsu RC is partially internalised in a coated pit with reduced clathrin condensation. Randomly distributed actin filaments are present in its vicinity (arrowheads). Surface ruffles are also participating in internalisation. D, Two morulae with $E$. sennetsu $\mathrm{RC}$ are still connected by their membranes after division of ehrlichiae. Neighbouring morulae contain RC and DC - one in each morula. 
(in cross-section) (Fig. 5B, C). The plasmalemma at the site of ingestion was thickened and resembled clathrin coating. Randomly distributed microfilaments were also present at this site (Fig. 5C).

One of the striking features of this ehrlichia was that reticulate and dense-cored cells were contained within individual vacuoles, even in heavily infected cells (Figs. 5D, 6A, B). They usually had an oval shape and sizes from $0.3 \times 0.7 \mu \mathrm{m}$ to $0.6 \times 1.0 \mu \mathrm{m}$ for reticulate cells and from $0.2 \times 0.3 \mu \mathrm{m}$ to $0.2 \times 0.5 \mu \mathrm{m}$ for dense-cored cells. The cell-wall membrane of reticulate cells was rather smooth, not very wavy, and was separated from the cytoplasmic membrane by a distinctly visible periplasmic space. The cytoplasmic membrane of some reticulate cells formed intraprotoplast invaginations that extended as deep as one-third of the diameter of the cell and in cross-sections appeared as intraprotoplast vesicles.

Both cell types in E. sennetsu divided by binary fission, and a remarkable feature was that the vacuolar membrane followed the separating daughter cells, occasionally with an isthmus (Figs. 5D, 6A) so that both ehrlichae were in individual morulae. Only rarely were two or three reticulate cells found within one morula. Often morulae contained small vesicles (30$70 \mathrm{~nm}$ in diameter) pinching off the cell-wall membrane, and the morula membrane, otherwise tightly apposed to the ehrlichial cell, was expanded to provide space for them (Fig. 6A, B). The intramorular space was usually very tight, and no matrix material was identified there.

E. sennetsu also developed a wide spectrum of abnormal forms. Those included giant reticulate cells that had an oval $(1.3 \times 2 \mu \mathrm{m})$, sausage $(0.8 \times 2.3 \mu \mathrm{m})$ or irregular, pleomorphic shape. Some irregularly shaped cells appeared to have resulted from the lack of separation of the protoplast of the daughter cells after incomplete division. The cytoplasmic membrane of both reticulate and dense-cored cells occasionally formed deep invaginations leading to a sequestration of a portion of their protoplast (Fig. 6B). Both limiting membranes of some reticulate cells developed extensions separating a part of the protoplast and surrounding it with multiple membranes (Fig. 6C).

Mitochondria did not concentrate adjacent to the morula in heavily infected cells. Short cisterns of granular endoplasmic reticulum were usually seen in close vicinity to the morula membrane.

\section{E. risticii}

In DH82 cells this ehrlichia formed both types of morulae: small ones enclosing individual reticulate or dense-cored cells and large round vacuoles containing many reticulate cells (c. 1.6-2.0 $\mu \mathrm{m}$ in diameter) (Figs. $6 \mathrm{D}, 7 \mathrm{~A}, \mathrm{~B})$. Morulae of intermediate size harboured a few (two to five) reticulate cells, and, interestingly, elongated, sausage-like morulae enveloped several oval or dividing dense-cored cells (up to six in a section) located along the long axis of this 'sausage' (Fig. 7B). Morphologically both cell types resembled those of $E$. sennetsu, but some reticulate cells had more wavy cell walls.

Large round morulae contained only reticulate cells, but they were of two different types: shorter oval ones with electron-lucent cytoplasm and longer bacillaryshaped ehrlichiae with electron-dense cytoplasm (Fig. 6D). The latter were often seen adjacent to the morula membrane. As in E. sennetsu, small vesicles were often seen in the morula cavity, but no other material was found in any of the morulae (Fig. 6D). The most common abnormalities in this ehrlichia were the formation of long cytoplasmic membrane invaginations and long cell wall projections, which sequestrated the protoplast or wrapped ehrlichiae within multiple membranes (Fig. 8A). Mitochondria were observed mostly near the small morulae (Fig. 7A). In the same heavily infected host cells harbouring morulae with normal appearing ehrlichiae, morulae with dense, irregularly shaped, electron-dense organisms that appeared non-viable were observed (Fig. 7A).

\section{W. pipientis}

This intracellular mosquito symbiont was studied in a continuous cell line Aa23, established from eggs of a naturally infected strain of the Asian tiger mosquito, Aedes albopictus [41].

Small round $(0.4 \mu \mathrm{m})$ or oval $(0.5 \times 1.0 \mu \mathrm{m})$ reticulate cells of wolbachiae were observed mostly in individual vacuoles (Fig. 8B, C) with the vacuolar membrane tightly apposed to the wolbachial cell wall. The cell-wall membrane was smooth, rather than wavy, and a narrow periplasmic space was seen in some locations along the circumference of the cell. Some cells were observed in the process of binary fission (Fig. 8B), and the vacuolar membrane followed the contours of the dividing cells. Intraprotoplast vesicles in some cells suggested invaginations of the cytoplasmic membrane. Intracellular dense-cored cells were not detected, but a few cells of this type $(0.4 \mu \mathrm{m}$ in diameter) were observed extracellularly, one of them being engulfed by a host cell (Fig. 8D). Large (up to $1.2 \mu \mathrm{m}$ in diameter) round reticulate cells were obseved in individual vacuoles (Fig. 8C). Large, elongated $(2.5 \times 8.6 \mu \mathrm{m})$ ehrlichiae as previously described were also present [41].

Many wolbachia-containing vacuoles were surrounded with a remarkable quantity of cisterns of granular endoplasmic reticulum (Fig. 8B). They were in tight contact with the vacuolar membrane and continued into the host cell cytoplasm, where they were often 

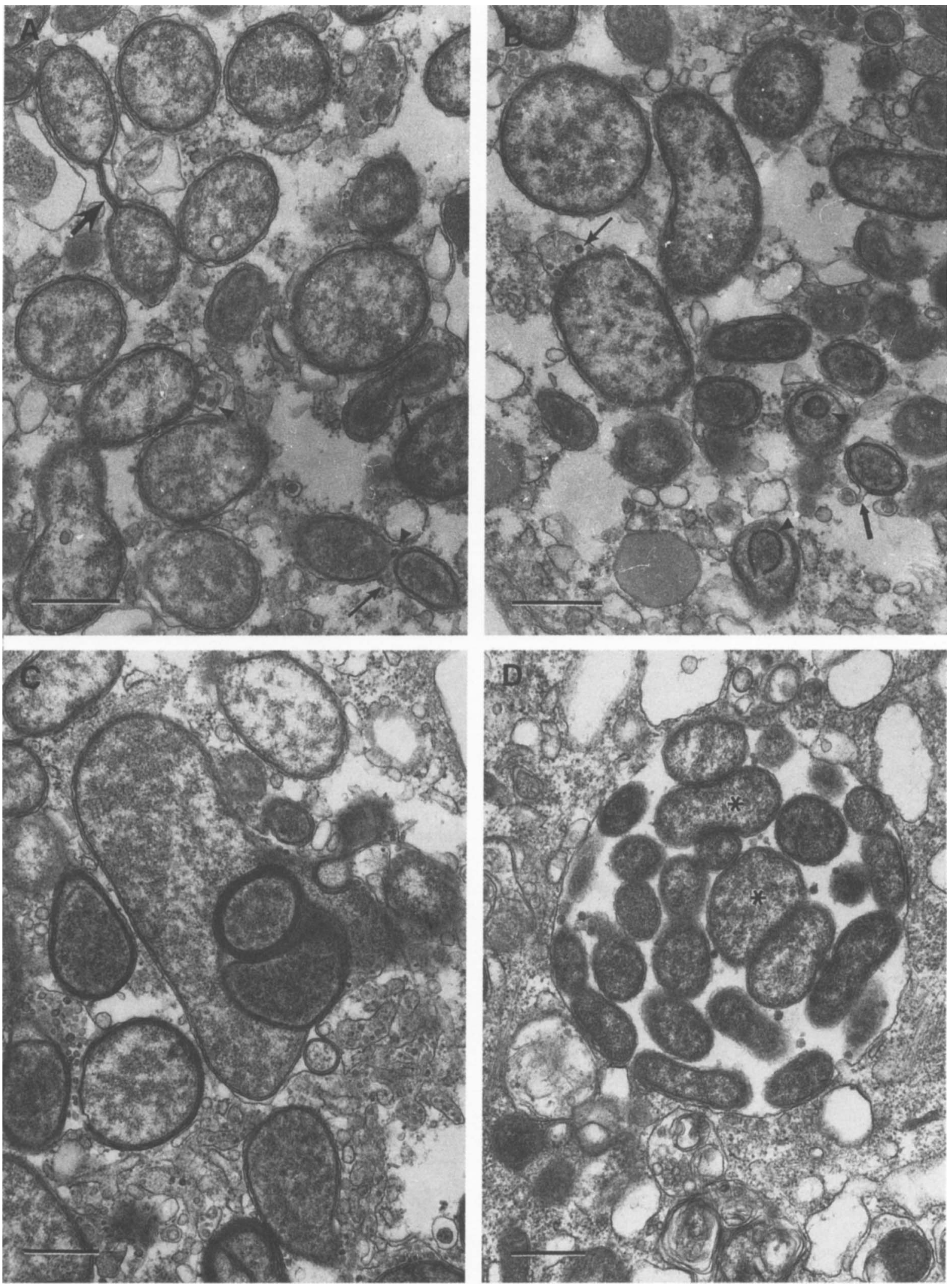

Fig. 6. E. sennetsu (Miyayama strain) and E. risticii (HRC-IL strain) in DH82. Bar $=0.5 \mu \mathrm{m}$. A, E. sennetsu morulae usually harbour one RC or DC. When ehrlichiae divide, the morula membrane follows the division of the ehrlichiae (arrows), either RC or DC, sometimes forming an isthmus (thick arrow) between two morulae. RC can pinch off vesicles into the morula cavity (arrowheads). B. Portions of $E$. sennetsu DC protoplast are sequestered by cytoplasmic membrane invaginations. Usually the morula membrane is apposed tightly to the ehrlichial cell surface, but sometimes it develops enlargements containing vesicles that apparently pinch off the cell-wall membrane of an $\mathrm{RC}$ (thin arrow), or appear to be fusing with cytoplasmic vesicles (thick arrow). C, Giant RC of E. sennetsu with complex limiting membrane invaginations, sequestrating portions of its protoplast. D, Morula of E. risticii contains two types of RC: oval lighter cells (asterisks) and denser bacillary-shaped ones. 

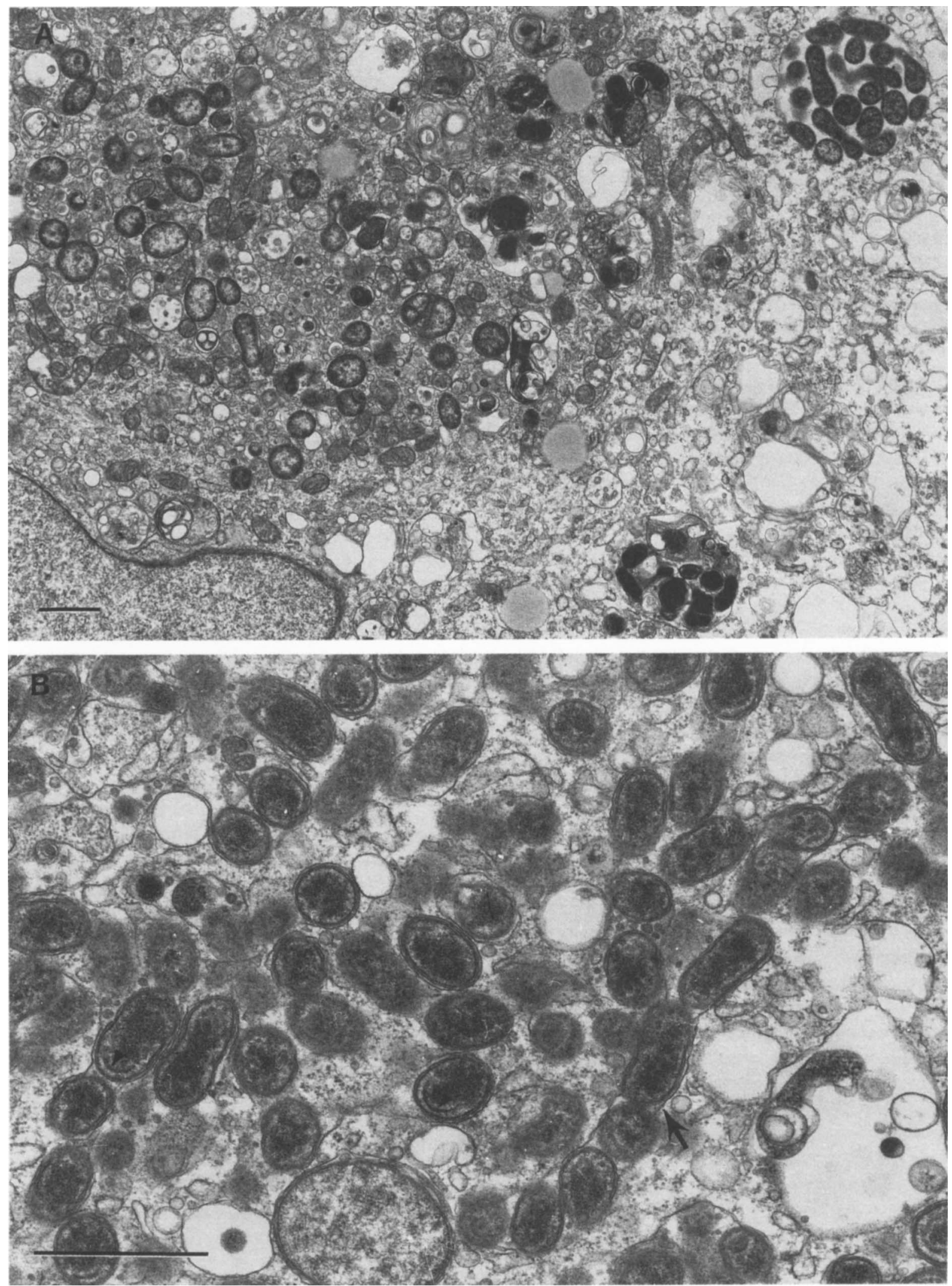

Fig. 7. Ultrastructure of E. risticii (HRC-IL strain) in DH82 cells. Bar $=1 \mu \mathrm{m}$. A, Different types of morulae in the cytoplasm of the host cell: many of them harbour individual ehrlichiae, some of which are dividing; one morula at the top right contains many RC, including dividing cells; a morula at the bottom contains dense, apparently degenerating ehrlichiae. B, Portion of the host cell cytoplasm heavily loaded with the morulae containing mostly DC ehrlichiae. After division they can produce a 'chain' of ehrlichiae within a tubule-like long morula (thick arrow). Some DC have cytoplasmic invaginations of the cytoplasmic membrane (arrowheads). 

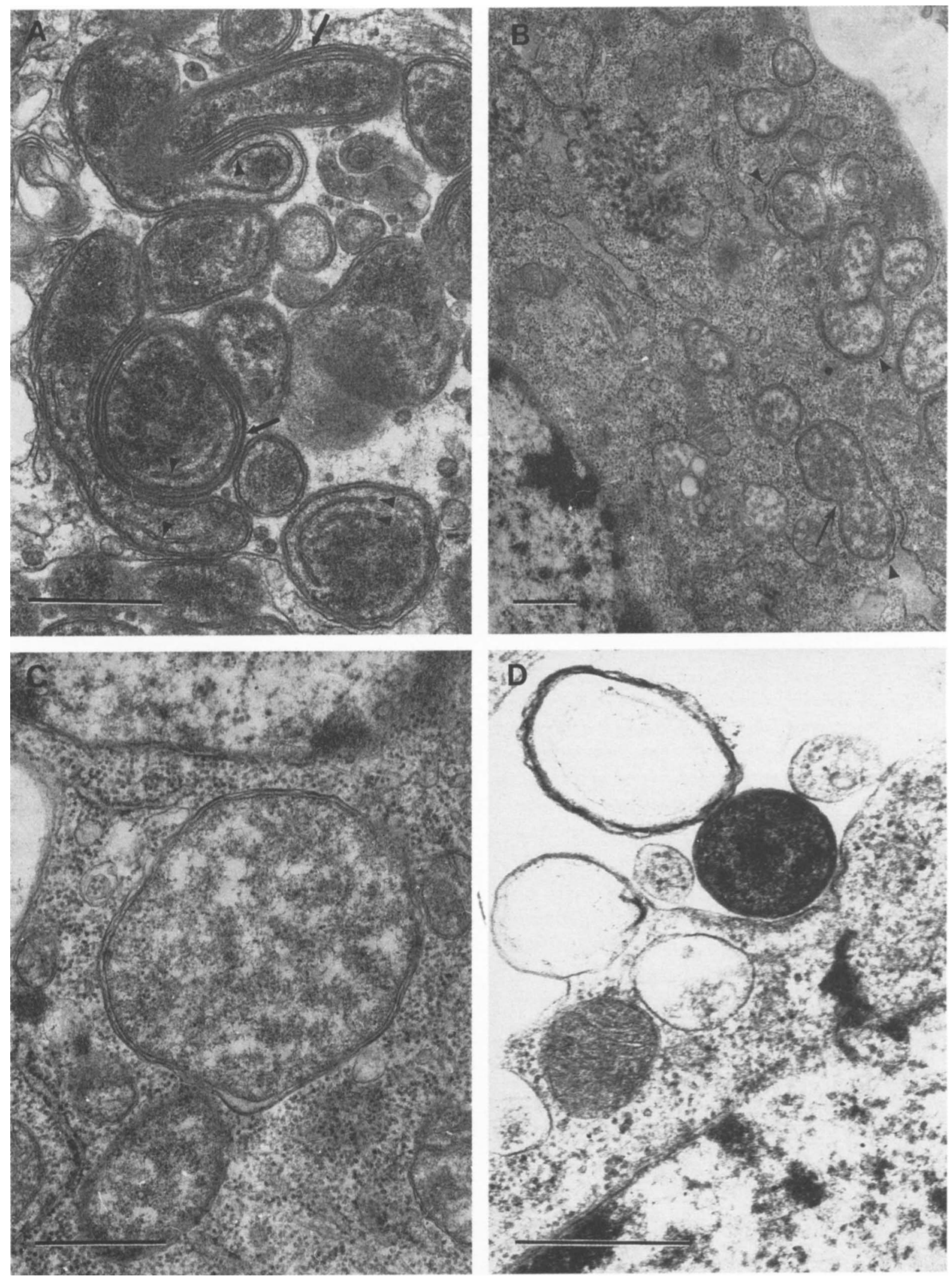

Fig. 8. E. risticii (HRC-IL strain) in canine DH82 and W. pipientis in mosquito Aa23 cells. Bar $=0.5 \mu \mathrm{m}$. A, Multiple cell-wall membrane protrusions (arrows) and cytoplasmic membrane invaginations (arrowheads) in E. risticii RC. B, W. pipientis $\mathrm{RC}$ are located in individual vacuoles. Some RC are dividing by binary fission (arrow). Distended granular endoplasmic reticulum cisterns can be in close contact with wolbachia-containing vacuoles (arrowheads). C, Parasitophorous vacuole in an Aa23 cell containing an RC-like cell of W. pipientis. D, A DC-like cell of W. pipientis in the process of internalisation by an Aa23 cell. Clathrin-like coating can be seen at the site of plasmalemma invagination. 
distended and filled with fine fibrillar material. Also, cytoplasmic vesicles were on occasion observed in contact with the vacuolar membrane. Mitochondria were located near parasitophorous vacuoles, but they were never in close contact with the morula membrane.

\section{Discussion}

This study investigated 15 isolates of ehrlichiae belonging to all three genogroups of the genus Ehrlichia and a strain of $W$. pipientis, which is related to this genus and represents a fourth clade in this cluster of species [9]. It is expected that in the future the taxonomy of these organisms will be revised after the completion of sufficient genetic analysis. There are many common features in ultrastructure uniting these organisms, and, on the other hand, a group of characteristics allows the genogroups to be distinguished ultrastructurally.

They are similar in the normal ultrastructure of individual cells and the formation of abnormal, pathological cells of the same type irrespective of the species. The differences are mostly in the structure of their microcolonies (morulae) and their interrelations with the host cells.

All ehrlichiae studied in cell culture existed in two morphological forms, reticulate and dense-cored cells. Both of them were found dividing, and this fact is evidence against the suggestion of a mandatory developmental cycle in these rickettsiae. Also, both cell types were found to be in various stages of internalisation by the host cells. Although both monocytes and granulocytes have an active phagocytic function, the study failed to demonstrate single ehrlichiae that appeared non-viable morphologically inside the phagolysosomes. This strongly suggests that most of the internalised parasites undergo multiplication in the parasitophorous vacuoles (morulae).

When E. muris and E. equi were studied in mouse organs or horse blood, respectively, dense-cored cells were never found. Several explanations could be offered: (a) dense-cored ehrlichiae do not exist in acute animal (or human) infection; (b) they are formed relatively infrequently, and the small quantities of morulae examined, compared to the cell culture model, did not allow their detection; (c) they form when the ehrlichial load per host cell is high, as in experimental infection of cell cultures, and this situation occurs only late in natural infections, or was not ahcieved in the infections of experimental animals; (d) some special host cell (or parasite?) factors or signals cause their formation.

Both cell types of ehrlichiae have a cell wall rather loosely connected with the ehrlichial cytoplasmic membrane. The degree of this looseness or waviness does not appear to be a species characteristic, but it might depend on the growth conditions. Peptidoglycan, responsible for the cell wall rigidity in gram-negative bacteria is not morphologically identified in ultra-thin sections of ehrlichiae. If present, it might have structure which would explain the fragility of ehrlichial cells. It also means that their shape has to be determined in different ways. The genus Cowdria has been said to possess a prominent peptidoglycan layer [45], but morphologically its cells are very similar to reticulate and dense-cored cells of ehrlichiae and no biochemical data have been reported [12-16].

Most reticulate and dense-cored cells have an oval or round shape. Only those in binary fission resemble small bacilli, but E. risticii (Fig. 6D) [46] and $E$. canis [36] can occur as longer bacilli, some of them being denser than others, or contacting the morula membrane, or both. The significance of these observations is unclear.

Extracellular ehrlichiae often have irregular shape, as in Cowdria [13, 14], or appear spheroplast-like. This appearance can be considered as evidence of their fragility in the extracellular environment.

All ehrlichiae studied have altered cells, both reticulate and dense-cored, and most of these alterations seem to be related to their membranes, especially the cell-wall membrane. They can be grouped at least in 10 groups (Fig. 9).

Most of these alterations were found in reticulate cells, and only intraprotoplast invaginations of the cytoplasmic membrane were common in dense-cored cells. The reasons for the appearance of pathological cells might be impairment of co-ordination between membrane growth and cell division (nos. 1 and 2), overproduction of cell wall material (nos. 3-5, 7), overproduction of cytoplasmic membrane (nos. 8-10), or both of them (no. 6). Vesicles in the morulae appeared to originate not only from the cell-wall membrane (no. 3), but also represented fragments of the protoplast surrounded by two membranes, resembling small mini-cells, or sometimes cross-sections of protoplast projections (no. 6). The mechanisms of these phenomena are not known, neither the factors that control them nor, for instance, the direction of growth of the cytoplasmic membrane (outside, into the periplasmic space, or inside, into the protoplast).

Many altered forms of similar kind have been described also in Anaplasma marginale and A. ovis in experimentally infected ticks [20, 47-50]: large reticulate cells, protoplast buds in periplasmic space, cell wall projections and pinched off vesicles from cell wall. Our interpretation is that these morphological forms represent a universal response of all ehrlichiae to changes in their intracellular environment and are 

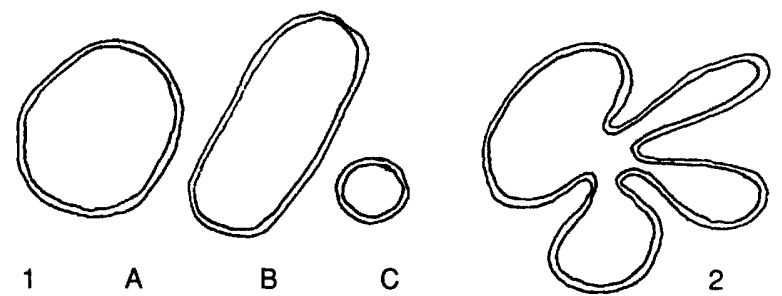

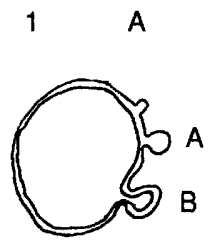

3

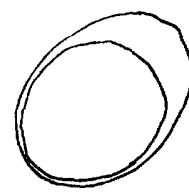

7

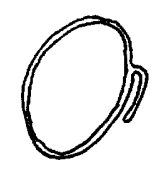

4

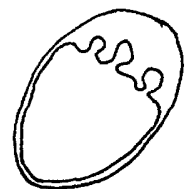

8

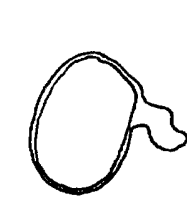

5

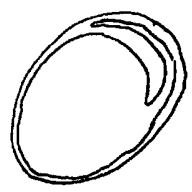

9

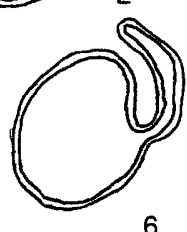

6

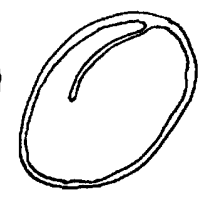

10
Fig. 9. Schematic representation of altered ehrlichial cells. 1, Large or even giant reticulate cells, round (A) or oval (B), with smooth contours, (C) CRC of a normal size; 2, multilobular giant reticulate cells, with deep separations of the protoplast; 3, variable-sized pinched off vesicles of the cell-wall membrane (A), or having cytoplasmic membrane inside (B); 4, formation of tubules of constant diameter of $25 \mathrm{~nm}$ by the cell-wall membrane; 5, projections of the cell-wall membrane of different widths; 6, projections of the whole envelope, including both cell-wall and cytoplasmic membrane; 7, expansions of the periplasmic space as in bacterial spheroplasts; 8 , protoplast buds into the periplasmic space; 9, protoplast or only cytoplasmic membrane projections into the periplasmic space; 10, deep invaginations of the cytoplasmic membrane into the protoplast.

similar to those of other gram-negative bacteria which respond by L-transformation [51, 52]. As in free-living bacteria, L-transformation might be a response to restrictive growth conditions and an adaptation for survival through subsequent reversion to normal cells, rather than the regular mode of multiplication. The regular mode of reproduction of ehrlichiae under permissive conditions is equal binary fission of both reticulate and dense-cored cells.

No special experiments studying the morphology of adherence and ingestion of ehrlichiae have been published, but the pictures observed in the present study suggest that for the $E$. sennetsu genogroup, both types of ehrlichial cells adhere to the host cell surface, are engulfed and initiate mulitplication in the phagosomes. Internalisation of $E$. risticii occurs through receptor-mediated endocytosis [53]. The data on $E$. sennetsu suggest that host cell ruffles participate in internalisation and the quantity of clathrin-like coating of the vesicle at the internalisation site is diminished.

Once inside a phagosome, E. risticii prevents its fusion with host cell lysosomes [31], but the data on this ehrlichia (Fig. 7A) and E. chaffeensis [37] suggest that under some cirucmstances destruction of the whole morula with its ehrlichiae occurs. This destruction occurs in the same area of the host cell cytoplasm where multiplying ehrlichiae are located in other morulae, an observation that would favour the hypothesis of a selective host cell-directed ehrlichiacidal mechanism.

Ehrlichiae, like most other bacteria, are internalised individually in separate phagosomes where they start to divide. In the E. canis and E. phagocytophila [32, 54-56] genogroups, their progeny remains in the same vacuole, which enlarges. For the genogroup consisting of E. sennetsu (see also [5]), E. risticii [46], $N$. helminthoeca [24] and SF-agent [25], the membrane of the parasitophorous vacuole follows the division of the enclosed parasite and expands and divides simultaneously with it (Figs. 5D, 6A). The signals providing this co-ordination are not known. Recently it was shown that Chlamydia trachomatis and C. psittaci direct their proteins into the phagosomal membrane structure [57]. When ultra-thin sections of E. chaffeensis-infected cells were incubated with polyclonal anti-ehrlichial antibodies, no particular localisation of the label in the morula limiting membrane was detected [37]. This result suggests the absence of antigenic ehrlichial proteins in this membrane, but further experiments are needed to elucidate this point.

All ehrlichiae of the $E$. canis group have a fibrillar matrix in their morula, which in E. chaffeensis is of ehrlichial origin [37] and contains the $120-\mathrm{kDa}$ protein (Walker, Yu, Popov, unpublished observations). Vacuoles containing $C$. ruminantium, A. marginale, and $A$. ovis also possess this kind of matrix $[12,14-16$, 19-21], although E. phagocytophila, E. equi and HGE morulae seem to be devoid of it $[29,39,55,56]$ (Figs. 3B, 4A, B). It is not clear whether or not the morula of the platelet-parasitising ehrlichia, E. platys [18], contains this substance. In the large vacuoles of E. risticii, similar material is either present in small quantity or absent altogether [46]. The importance of this material is not known, but it might be a step in the transportation of ehrlichial antigens to the host cell surface, where they have been shown to be exposed [35].

Exit of ehrlichiae from large morulae of $E$. canis, $E$. muris, E. chaffeensis, $\mathrm{HGE}$ and $E$. risticii seems to occur via rupture of both the morula membrane and the adjacent host cell plasmalemma when the morula is located at the periphery of the cell.

Intracellular multiplication of ehrlichiae does not appear to injure the host cell until late in the infection, even under experimental conditions of heavy infection. The most prominent reaction of the host cell is concentration of mitochondria near the morulae of the $E$. canis group and tight contacts of the cisterns of granular endoplasmic reticulum membranes with the 
morula membrane in the $E$. canis genogroup and $W$. pipientis.

From the data described it seems possible to summarise the following morphological differences between infections with the various genogroups. (1) The E. canis-E. chaffeensis group forms large morulae with many ehrlichiae, often suspended in fibrillar matrix. Host cell mitochondria and endoplasmic reticulum usually are in contact with the morula membrane and aggregate near the morulae. (2) The $E$. phagocytophila-HGE group morulae have no fibrillar matrix, no contacts with host cell mitochondria and no aggregation of mitochondria around the morulae. (3) The E. sennetsu-E. risticii group usually develop in small individual vacuoles that do not fuse with each other. These characteristics allow the differentiation of ehrlichiae at the ultrastructural level.

We are grateful to Josie Ramirez for valuable and expert help in the preparation of this manuscript. This research was supported by grants from the National Institutes of Health (AI 31431) and the Mac Arthur Foundation.

\section{References}

1. Smith RD, Sells DM, Stephenson EH, Ristic MR, Huxsoll DL. Development of Ehrlichia canis, causative agent of canine ehrlichiosis, in the tick Rhipicephalus sanguineus and its differentiation from a symbiotic rickettsia. Am J Vet Res 1976; 37: $119-126$

2. Anderson BE, Sims KG, Olson JG et al. Amblyomma americanum: a potential vector of human ehrlichiosis. $A m J$ Trop Med Hyg 1993; 49: 239-244.

3. Magnarelli LA, Stafford KC, Mather TN, Yeh M-T, Horn KD, Dumler JS. Hemocytic rickettsia-like organisms in ticks: serologic reactivity with antisera to ehrlichiae and detection of DNA of agent of human granulocytic ehrlichiosis by PCR. $J$ Clin Microbiol 1995; 33: 2710-2714.

4. Pancholi P, Kolbert CP, Mitchell PD et al. Ixodes dammini as a potential vector of human granulocytic ehrlichiosis. $J$ Infect Dis 1995; 172: 1007-1012.

5. Kelly DJ, Lee M, Lewis GE. A light and electron microscopic examination of Ehrlichia sennetsu in cultured human endothelial cells. Jpn J Med Sci Biol 1985; 38: 155-168.

6. Maeda K, Markowitz N, Hawley RC, Ristic M, Cox D, McDade JE. Human infection with Ehrlichia canis, a leukocytic rickettsia. $N$ Engl J Med 1987; 316: 853-856.

7. Anderson BE, Dawson JE, Jones DC, Wilson KH. Ehrlichia chaffeensis, a new species associated with human ehrlichiosis. J Clin Microbiol 1991; 29: 2838-2842.

8. Chen S-M, Dumler JS, Bakken JS, Walker DH. Identification of a granulocytotropic Ehrlichia species as the etiologic agent of human disease. J Clin Microbiol 1994; 32: 589-595.

9. Walker DH, Dumler JS. Emergence of the ehrlichioses as human health problems. Emerg Infect Dis 1996; 2: 18-29.

10. Kawahara M, Suto C, Rikihisa Y, Yamamoto S, Tsuboi Y. Characterization of ehrlichial organisms isolated from a wild mouse. J Clin Microbiol 1993; 31: 89-96.

11. Wen B, Rikihisa Y, Mott Y, Fuerst PA, Kawahara M, Suto C. Ehrlichia muris sp. nov., identified on the basis of 16S rRNA base sequences and serological, morphological, and biological characteristics. Int J Syst Bacteriol 1995; 45: 250-254.

12. Hart A, Kocan KM, Bezuidenhout JD, Prozesky L. Ultrastructural morphology of Cowdria ruminantium in midgut epithelial cells of adult Amblyomma hebraeum female ticks. Onderstepoort $J$ Vet Res 1991; 58: 187-193.

13. Jongejan F, Zandbergen TA, van de Wiel PA, de Groot $M$, Uilenberg G. The tick-borne rickettsia Cowdria ruminantium has a Chlamydia-like developmental cycle. Onderstepoort $J$ Vet Res 1991; 58: 227-237.
14. Kocan KM, Bezuidenhout JD. Morphology and development of Cowdria ruminantium in Amblyomma ticks. Onderstepoort $J$ Vet Res 1987; 54: 177-182.

15. Kocan KM, Bezuidenhout JD, Hart A. Ultrastructural features of Cowdria ruminantium in midgut epithelial cells and salivary glands of nymphal Amblyomma hebraeum. Onderstepoort $J$ Vet Res 1987; 54: 87-92.

16. Kocan $\mathrm{KM}$, Morzaria SP, Voigt WP, Kiarie J, Irvin $\mathrm{AD}$. Demonstration of colonies of Cowdria ruminantium in midgut epithelial cells of Amblyomma variegatum. Am J Vet Res 1987; 48: $356-360$.

17. Dumler JS, Asanovich KM, Bakken JS, Richter P, Kimsey R, Madigan JE. Serologic cross-reactions among Ehrlichia equi, Ehrlichia phagocytophila, and human granulocytic ehrlichia. $J$ Clin Microbiol 1995; 33: 1098-1103.

18. Harvey JW, Simpson CF, Gaskin JM. Cyclic thrombocytopenia induced by a Rickettsia-like agent in dogs. J Infect Dis 1978; 137: $182-188$.

19. Kocan KM, Stich RW, Claypool PL, Ewing SA, Hair JA, Barron SJ. Intermediate site of development of Anaplasmo marginale in feeding adult Dermacentor andersoni ticks that were infected as nymphs. Am J Vet Res 1990; 51: 128-132.

20. Kocan KM, Stiller D. Development of Anaplasma ovis (Rickettsiales: Anaplasmataceae) in male Dermacentor andersoni (Acari: Ixodidae) transferred from infected to susceptible sheep. J Med Entomol 1992; 29: 98-107.

21. Kocan KM, Stiller D, Goff WL et al. Development of Anaplasma marginale in male Dermacentor andersoni transferred from parasitemic to susceptible cattle. Am J Vet Res 1992; 53: 499-507.

22. Chaichanasiriwithaya W, Rikihisa $\mathrm{Y}$, Yamamoto $\mathrm{S}$ et al. Antigenic, morphologic, and molecular characterization of new Ehrlichia risticii isolates. J Clin Microbiol 1994; 38: 3026-3033.

23. Rikihisa Y. Cross-reacting antigens between Neorickettsia helminthoeca and Ehrlichia species, shown by immunofluorescence and western immunoblotting. J Clin Microbiol 1991; 29: 2024-2029.

24. Rikihisa Y, Stills H, Zimmerman G. Isolation and continuous culture of Neorickettsia helminthoeca in a macrophage cell line. J Clin Microbiol 1991; 29: 1928-1933.

25. Wen B, Rikihisa Y, Yamamoto S, Kawabata N, Fuerst PA Characterisation of the SF agent, an Ehrlichia sp. isolated from the fluke Stellantchasmus falcatus, by $16 \mathrm{~S}$ rRNA base sequence, serological, and morphological analyses. Int $J$ Syst Bacteriol 1996; 46: 149-154.

26. Brouqui P, Birg ML, Raoult D. Cytopathic effect, plaque formation, and lysis of Ehrlichia chaffeensis grown on continuous cell lines. Infect Immun 1994; 62: 405-411.

27. Chen S-M, Popov VL, Feng H-M, Wen J, Walker DH Cultivation of Ehrlichia chaffeensis in mouse embryo, Vero, BGM, and L929 cells and study of Ehrlichia-induced cytopathic effect and plaque formation. Infect Immun 1995; 63: $647-655$.

28. Goodman JL, Nelson C, Vitale B et al. Direct cultivation of the causative agent of human granulocytic ehrlichiosis. $N$ Engl $J$ Med 1996; 334: 209-215.

29. Munderloh UG, Madigan JE, Dumler JS et al. Isolation of the equine granulocytic ehrlichiosis agent, Ehrlichia equi, in tick cell culture. J Clin Microbiol 1996; 34: 664-670.

30. Rikihisa Y, Perry BD. Causative ehrlichial organisms in Potomac horse fever. Infect Immun 1985; 49: 513-517.

31. Wells MY, Rikihisa Y. Lack of lysosomal fusion with

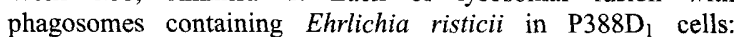
abrogation of inhibition with oxytetracycline. Infect Immun 1988; 56: 3209-3215.

32. Rikihisa Y. The tribe Ehrlichieae and ehrlichial diseases. Clin Microbiol Rev 1991; 4: 286-308.

33. Dawson JE, Rikihisa Y, Ewing SA, Fishbein DB. Serologic diagnosis of human ehrlichiosis using two Ehrlichia canis isolates. J Infect Dis 1991; 163: 564-567.

34. Dawson JE, Anderson BE, Fishbein DB et al. Isolation and characterization of an Ehrlichia sp. from a patient diagnosed with human ehrlichiosis. J Clin Microbiol 1991; 29: $2741-2745$.

35. Messick JB, Rikihisa Y. Presence of parasite antigen of the surface of $\mathrm{P}_{388 \mathrm{D}_{1}}$ cells infected with Ehrlichia risticii. Infect Immun 1992; 60: 3079-3086.

36. Iqbal Z, Rikihisa Y. Reisolation of Ehrlichia canis from blood 
and tissues of dogs after doxycycline treatment. $J$ Clin Microbiol 1994; 32: 1644-1649.

37. Popov VL, Chen S-M, Feng H-M, Walker DH. Ultrastructural variation of cultured Ehrlichia chaffeensis. $J$ Med Microbiol 1995; 43: 411-421.

38. Dumler JS, Chen S-M, Asanovich K, Trigiani E, Popov VL, Walker DH. Isolation of characterization of a new strain of Ehrlichia chaffeensis from a patient with nearly fatal monocytic ehrlichiosis. J Clin Microbiol 1995; 33: 1704-1711.

39. Rikihisa Y, Zhi N, Wormser GP, Wen B, Horowitz HW, Hechemy KE. Ultrastructural and antigenic characterization of a granulocytic ehrlichiosis agent directly isolated and stably cultivated from a patient in New York state. J Infect Dis 1997; 175: $210-213$.

40. Chen S-M, Yu X-J, Popov VL, Westerman EL, Hamilton FG, Walker DH. Genetic and antigenic diversity of Ehrlichia chaffeensis: comparative analysis of a novel human strain from Oklahoma and previously isolated strains. J Infect Dis 1997; 175: $856-863$.

41. O'Neill SL, Pettigrew MM, Sinkins SP, Braig HR, Andreadis TG, Tesh RB. In vitro cultivation of Wolbachia pipientis in an Aedes albopictus cell line. Insect Mol Biol 1997; 6: 33-39.

42. Madigan JE, Richter PJ, Kimsey RB, Barlough JE, Bakken JS, Dumler JS. Transmission and passage in horses of the agent of human granulocytic ehrlichiosis. J Infect Dis 1995; 172: 1141-1144.

43. Ito S, Rikihisa Y. Techniques for electron microscopy of rickettsiae. In: Burgdorfer W, Anacker RL (eds) Rickettsiae and rickettsial diseases. New York, Academic Press. 1981: 213-227.

44. Perez M, Rikihisa Y, Wen B. Ehrlichia canis-like agent isolated from a man in Venezuela: antigenic and genetic characterization. J Clin Microbiol 1996; 34: 2133-2139.

45. Rikihisa Y, Logan LL. Unusual peptidoglycan-like substance in Cowdria ruminantium in the endothelial cells of the choroid plexus of the goat. Proceedings of the XIth International Congress on Electron Microscopy 1986; 3345-3346.

46. Rikihisa Y, Perry BD, Cordes DO. Ultrastructural study of ehrlichial organisms in the large colons of ponies infected with Potomac horse fever. Infect Immun 1985; 49: 505-512.

47. Kocan KM, Hair JA, Ewing SA. Ultrastructure of Anaplasma marginale Theiler in Dermacentor andersoni Stiles and Dermacentor variabilis (Say). Am $J$ Vet Res 1980; 41: 1966-1976.

48. Kocan KM, Ewing SA, Holbert D, Hair JA. Morphologic characteristics of colonies of Anaplasma marginale Theiler in midgut epithelial cells of Dermacentor andersoni Stiles. Am J Vet Res 1982; 43: 586-593.

49. Potgieter FT, Kocan KM, McNew RW, Ewing SA. Demonstration of colonies of Anaplasma marginale in the midgut of Rhipicephalus simus. Am J Vet Res 1983; 44: 2256-2261.

50. Kocan KM, Yellin TN, Ewing SA, Hair JA, Barron SJ Morphology of colonies of Anaplasma marginale in nymphal Dermacentor andersoni. Am J Vet Res 1984; 45: 1434-1440.

51. Avakyan AA, Popov VL. Rickettsiaceae and Chlamydiaceae: comparative electron microscopic studies. Acta Virol 1984; 28 159-173.

52. Domingue GJ, Woody HB. Bacterial persistence and expression of disease. Clin Microbiol Rev 1997; 10: 320-344.

53. Rikihisa Y, Zhang Y, Park J. Inhibition of infection of macrophages with Ehrlichia risticii by cytochalasins, monodansylcadaverine, and taxol. Infect Immun 1994; 62: $5126-$ 5132.

54. Hildebrandt PK, Conroy JD, McKee AE, Nyindo MBA, Huxsoll DL. Ultrastructure of Ehrlichia canis. Infect Immun 1973; 7: 265-271.

55. Tuomi J, von Bonsdorff C-H. Electron microscopy of tickborne fever agent in bovine and ovine phagocytizing leukocytes. J Bacteriol 1996; 92: 1478-1492.

56. Sells DM, Hildebrandt PK, Lewis GE, Nyindo MBA, Ristic M. Ultrastructural observations on Ehrlichia equi organisms in equine granulocytes. Infect Immun 1976; 13: 273-280.

57. Taraska T, Ward DM, Ajioka RS et al. The late chlamydial inclusion membrane is not derived from the endocytic pathway and is relatively deficient in host proteins. Infect Immun 1996; 64: $3713-3727$. 